\title{
Décès du professeur Gejza Mencer
}

C'est avec une grande tristesse que le CICR a appris récemment le décès à l'âge de 83 ans du professeur Gejza Mencer, membre du Comité fédéral de la Croix-Rouge tchécoslovaque, expert de renommée mondiale dans le domaine du droit international humanitaire.

Professeur de droit international public, chercheur à l'Académie des sciences tchécoslovaque, président de la sous-commission de la Croix-Rouge tchécoslovaque sur le droit international humanitaire, le professeur Mencer s'est consacré pendant de nombreuses années, tant sur les plans national et international, au développement et à la diffusion du droit international humanitaire et des principes et idéaux de la Croix-Rouge.

Vice-président de 1979 à 1981 du «Groupe conjoint CICR-Ligue des Sociétés de la Croix-Rouge pour la diffusion du droit international humanitaire et des principes et idéaux de la Croix-Rouge», il représenta la Croix-Rouge tchécoslovaque au sein de la délégation de son pays à la Conférence diplomatique sur la réaffirmation et le développement du droit international humanitaire applicable dans les conflits armés (1974-1977) et fut membre, de 1973 à 1986, de la délégation de cette Société nationale dans un grand nombre de réunions internationales du Mouvement international de la Croix-Rouge et du CroissantRouge. Il a donné, en outre, des conférences dans de nombreuses universités étrangères et il est l'auteur d'ouvrages et d'études sur les Protocoles additionnels aux Conventions de Genève, le droit international public et la protection internationale de l'environnement.

D'une grande finesse d'esprit et de tempérament communicatif, il sut faire partager à nombre d'étudiants sa passion pour le droit et l'action humanitaires. Ses compétences professionnelles, sa personnalité généreuse et ses dons oratoires lui ont valu considération et respect, tant dans son pays qu'à l'étranger.

Le professeur Mencer s'est vu décerner la Médaille Henry-Dunant en 1989 en reconnaissance de son dévouement inlassable à la cause de la protection de la personne humaine en temps de conflit armé.

Le CICR gardera un souvenir ému et reconnaissant de ce grand serviteur de la cause humanitaire. 